\title{
El reformismo universitario, la juventud y la política en los "explosivos" sesentas: el caso del movimiento estudiantil de La Plata en la coyuntura del Cordobazo
}

\author{
Nayla Pis Diez \\ CONICET/Instituto de Investigaciones en Humanidades y Ciencias Sosciales - \\ Universidad Nacional de La Plata, Argentina \\ nayla.pdiez@gmail.com
}

\section{ReSUMEN:}

Este trabajo propone reconstruir los sucesos que marcaron las calles de la ciudad de La Plata entre 1968 y 1969. Con este telón de fondo, nos enfocaremos en cómo impactó el Cordobazo en dicha ciudad y más precisamente en los discursos y las acciones de su movimiento estudiantil. El foco lo colocaremos en dicho actor, intentando precisar sus corrientes internas y las formas como estas se identificaban y enunciaban a la Reforma Universitaria.

Palabras Clave: Movimiento Estudiantil, La Plata, Cordobazo, Reformismo, Peronismo.

\begin{abstract}
:
This article aims to reconstruct the events that mark the streets of the city of La Plata between 1968 and 1969. With this backdrop, we will focus on how impacted the Cordobazo in this city and more precisely in the speeches and actions of its student movement . The focus will place on that actor, with precision, in their internal currents and in the ways they identified with the University Reform.
\end{abstract}

KeYworDs: Student Movement, La Plata city, Cordobazo, Reformism, Peronism.

\section{INTRODUCCIón}

Desde 1955 hasta la última dictadura militar, nuestro país vivió una etapa marcada por el agotamiento del modelo de acumulación de industrialización por sustitución de importaciones y una fuerte crisis de legitimidad del sistema político, sus instituciones y reglas generales. De acuerdo a los estudios clásicos, el golpe militar que en junio de 1966 derrocó a Arturo Illia, representó un intento de clausura de dicho ciclo a través de mecanismos políticos autoritarios, como el cierre del Congreso, y medidas económicas tendientes a "racionalizar" la economía y disciplinar a los trabajadores (O' Donnell, 2009; James, 2010). Pero todo ello no hizo más que cultivar un campo de protesta de sectores sociales afectados, siendo sus polos más dinámicos un sindicalismo pronto cohesionado en la CGT de los Argentinos (CGTA) y el movimiento estudiantil. Así, una "ola de desobediencia social generalizada" provocó durante 1969 fuertes movilizaciones en las ciudades de Corrientes, Rosario, Tucumán, La Plata o Córdoba, prolongándose hasta 1971 y marcando el fin del proyecto autoritario de la Revolución Argentina (James, 2010; Gordillo, 2003).

Siempre que nos proponemos ensayar cronologías y esquemas de comprensión de nuestra historia reciente, dos años aparecen como claves para ello. Los últimos dos de la década del sesenta, 1968 y 1969 (y quizás un poco más el segundo) constituyen momentos donde esa historia se condensó, es decir, donde procesos subterráneos se mostraron en conjunción y con total claridad. Fueron también años catalizadores, en los que la historia, aquellos procesos, las experiencias de vida y militancia, se proyectaron y comenzaron a transformar con gran vertiginosidad todos los campos, el mundo obrero, católico, intelectual, el peronismo y las izquierdas. La gestación de un sentimiento de oposición a la dictadura, entremezclado con un ya conocido hartazgo hacia la inestabilidad e ilegitimidad del sistema político argentino, es uno de esos procesos que se 
mostraba ineludible para 1969. Concretamente, para Mónica Gordillo (2003) ese año fue un "momento explosivo": emergió lo acumulado y estalló aquel hartazgo generalizado en forma de acción directa, protestas obreras, estudiantiles y luego, rebeliones populares. Al mismo tiempo, diversos estudios clásicos señalan que en esos años emergió la "juventud" como actor político y colectivo en la esfera pública. En un clásico trabajo a propósito del "Cordobazo", Juan Carlos Torre (1994) señala que dos historias se encontraron en las calles de la ciudad mediterránea en 1969: por un lado, la de las poblaciones trabajadoras y sus sindicatos, expulsados de la vida política en 1955; por otro, la de las juventudes de clases medias, atravesadas por el proceso general de radicalización y una suerte de "extrañamiento" respecto de las instituciones y las ideas ordenadoras de la vida política, familiar, educativa. Un poco más cerca, Valeria Manzano (2017) coincide con la apreciación sobre la coyuntura, para ella, 1968/1969 "catapultó" a los jóvenes hacia el papel de actores políticos visibles, dejando a la luz profundas transformaciones ideológicas en dicho estrato. De acuerdo a la autora, el espacio político que mejor capitalizó la novedad generacional fue el peronismo, mediante los atinados discursos del líder en el exilio y el llamado a "fundirse con el pueblo". Una buena ilustración de ello se encuentra en el movimiento estudiantil, donde las agrupaciones peronistas y católicas habrían suplantado al reformismo universitario con fuertes críticas a sus banderas clásicas y a un supuesto encierro en una universidad que, se entendía, "era parte del pasado" (p. 252).

En el campo de estudios sobre el movimiento estudiantil argentino, el tema suscitado alrededor de la radicalización juvenil y el lugar del peronismo en los finales sesentas, se ha convertido en toda una línea de indagación. Por un lado, pioneros estudios señalan que la cultura juvenil contestataria se habría traducido en una crisis u "agotamiento histórico" del movimiento reformista, abonado por una pérdida de especificidad en sus demandas en desmedro de la lucha política revolucionaria (Ceballos, 1985; Alzogaray y Crespo, 1994). No es poca la bibliografía académica y testimonial que, en sintonía con Manzano, encuentra que el peronismo logró constituirse como uno de los actores que logró acumular políticamente dicha crisis, creciendo en las universidades a partir de fuertes críticas a la Reforma (Barletta, 2000; Recalde y Recalde, 2007). Frente a esto, otros autores han puesto el foco en la reconfiguración del reformismo, en el marco de un gobierno represivo y un ciclo nacional de protestas como fuera el de 1968/1969, matizando así las afirmaciones de "agotamiento" de las organizaciones inscriptas en el movimiento de 1918 (Millán, 2013; Califa y Bonavena, 2018). El objetivo de este artículo es aportar tanto a esas lecturas generales como al debate reseñado, a partir de un caso en particular, el de la juventud universitaria de La Plata, sus acciones y discursos en el marco de aquella coyuntura decisiva para la vida política del país como fuera la que rodeó el Cordobazo.

Muchas de las características cuantitativas y cualitativas reseñadas por Alzogaray y Crespo (1994) para los estudiantes cordobeses del '69 nos recuerdan a los platenses: importantes comunidades de estudiantes de otros pueblos, regiones y países; barrios repletos de pensiones que las albergaban, Centros de Estudiantes que los organizaban y un Comedor Universitario con sus almuerzos cenas y bailes. Ahora bien, creemos que un aporte a aquellos debates generales debe dar cuenta de esas particularidades así como también debe atender a las identidades políticas en pugna en 1969, a la relación entre las diversas corrientes estudiantiles y el movimiento obrero, y al peso real del reformismo entre las agrupaciones estudiantiles y la Federación Universitaria. Es que si bien a priori podemos decir que la oposición a la dictadura y al ilegítimo sistema político eran sentidos extendidos en el estudiantado, de ello no se desprende una pérdida de credibilidad igual de profunda hacia el reformismo y sus organismos. Y aunque es un hecho que el peronismo y nuevas corrientes de izquierda crecieron apuntalados por ese discurso, es importante observar sus causas particulares, sus temporalidades y matices; en fin, creemos que la lectura general debe comprobarse a través de un análisis concreto y empírico.

Tomando estas cuestiones generales, podemos decir que este trabajo propone reconstruir los sucesos que marcaron las calles de la ciudad de La Plata entre 1968 y 1969. Con este telón de fondo, nos enfocaremos en cómo impactó el Cordobazo en dicha ciudad y más precisamente en los discursos y las acciones de su movimiento estudiantil. El foco lo colocaremos en dicho actor, intentando precisar sus corrientes 
internas y las formas como estas se identificaban y enunciaban a la Reforma Universitaria: ¿qué se decía del reformismo en general, y, en particular, del reformismo en 1969? ¿Se crearon nuevos espacios organizativos? ¿Estos, anularon a los reformistas o convivieron con ellos? Indagaremos también sobre cómo impactaron las movilizaciones de 1969 en ese mapa, reparando en las acciones llevadas a cabo y las alianzas que se tramaron. Resta decir que este trabajo encuentra un cimiento fundamental en las fuentes documentales escritas, particularmente, han sido de enorme utilidad registros de diarios locales con detallada y abundante información sobre la Universidad y la ciudad; también el acceso a los documentos de espionaje elaborados por la Dirección de Inteligencia de la Policía de Buenos Aires (DIPBA), hoy desclasificados por la Comisión por la Memoria (CPM) y a revistas del período que encontramos en el Archivo Nacional de la Memoria; por último, ha sido de enorme utilidad la cronología nacional de hechos protagonizados por el movimiento estudiantil, elaborada por Pablo Bonavena, gentilmente cedida a la autora.

\section{Los años PREvios: EL ESCENARIO PLATENSE ENTRE LA RESISTENCIA DE 1966 Y EL "INVIERNO CALIENTE" DE 1968}

Durante los meses de abril, mayo y junio de 1966 las universidades nacionales se encontraban en medio de un ciclo de protestas por mayor presupuesto, que se remonta a 1963. Por esos meses, las movilizaciones estudiantiles, los incidentes con las fuerzas policiales y las detenciones de estudiantes fueron el saldo de cada jornada de protesta. Así estaban las cosas en la UNLP cuando el día 28 de junio se produjo el golpe militar que derrocó el gobierno del radical Arturo Illia. El mismo día del golpe, fuerzas policiales se instalaron en los accesos del Rectorado y de varias facultades impidiendo la entrada de estudiantes y personal. Y aunque las detenciones y el enfrentamiento estudiantil con las fuerzas policiales fueron moneda corriente durante casi toda la década de 1960, el año 1966 marcó algunas novedades, entre ellas, la presencia constante de fuerzas represivas en las calles y en la Universidad. Es que casi la única manifestación inmediata de hostilidad se dio entre algunos actores de las universidades nacionales, ya colocadas en la mira de la opinión pública debido a las denuncias de "infiltración marxista". La sanción del Decreto-Ley n. ${ }^{\circ} 16.912$ a fines de julio y las intervenciones sobre las universidades, fueron un punto de inflexión en el año. La normativa suprimía el gobierno tripartito y obligaba a los rectores y decanos a transformarse en interventores del Ministerio del Interior. En Ciudad de Buenos Aires, la facultad de Exactas, tomada por alumnos y profesores, fue desalojada violentamente por las fuerzas militares, dejando como saldo un grupo considerable de detenidos y fuertes imágenes del hecho luego conocido como la "Noche de los bastones largos". En la UNLP nos encontramos un escenario caracterizado, por un lado, por la inexistencia de renuncias masivas; por otro, por una "convivencia obligada" entre los interventores y un claustro de profesores que manifestaba abiertamente su desacuerdo con el régimen. A tono con este escenario general, podemos decir que el desacuerdo masivo con el régimen militar se expresó a través de varias líneas de acción. Primero, renuncias importantes, pues en pocos días presentaron sus dimisiones el Rector, todos los Decanos y los directores de Escuelas y Colegios universitarios. En segundo lugar, se establecieron asambleas interclaustro de docentes no renunciantes. La excepción a esto la encontramos en la facultad de Arquitectura donde entre los días 12 y 13 de agosto renunciaron 80 docentes con apoyo del Centro de Estudiantes y tres profesores de la facultad de Humanidades. ${ }^{1}$

Este escenario quedaría incompleto si no hiciéramos mención a la actividad estudiantil, heterogénea, pero encabezada por una FULP que asumió una actitud opositora inmediata. Al otro día de que fuera sancionada la nueva normativa universitaria, la entidad manifestó su oposición convocando a la defensa de la universidad democrática y reformista así como también llamando a los profesores a no renunciar. Tanto el reformismo como el movimiento estudiantil platense se encontraba atravesado por diversas líneas que, luego del golpe militar, continuaron e incluso se acentuaron. Por un lado, los Centros de Estudiantes de Humanidades, Bellas Artes, Arquitectura, Medicina y Naturales, todos ellos dirigidos por agrupaciones reformistas de izquierdas, elaboraron sus declaraciones en conjunto, con un tono menos corporativo y menos universitario que las 
elaboradas por una FULP conducida por espacios reformistas poco propensos a manifestarse políticamente. Por fuera de la FULP, surgieron numerosos espacios manifestando un fuerte apoyo al golpe militar y un discurso tan antirreformista como contrario a lo que denominaban el "bolchevismo destructor" de la universidad y el orden nacional.

En agosto particular impacto tuvo lo sucedido en Córdoba, donde, el día 18 la represión a una movilización al Hospital de Clínicas dejó 200 detenidos. El mismo día, un grupo de estudiantes integralistas decidieron comenzar una huelga de hambre en la Parroquia Cristo Obrero, contra la Ley universitaria y por la renuncia del Ministro del Interior. Encuentra Pablo Bonavena (2006) que con el correr de los días, la medida se replicó en Chaco, Corrientes y San Luis, con huelgas de hambre realizadas por estudiantes integralistas en solidaridad con los estudiantes cordobeses. En La Plata, manifestaron su apoyo con la osada medida el Centro de Estudiantes de Medicina, el de Humanidades y también una decena de agrupaciones socialcristianas. A partir de aquí, en cada manifestación estudiantil las iglesias de la ciudad contarán con guardia especial.

El 25 de agosto tuvo lugar además el nombramiento de las nuevas autoridades universitarias, del rectorinterventor Santiago Gorostiague y los decanos de buena parte de las facultades. A los pocos días, las casas de Gorostiague y Antonio Bonet, interventor de Humanidades, fueron atacadas con bombas de alquitrán. Ambas cuestiones, la radicalidad del estudiantado nacional y los cambios locales, colaboraron en radicalizar las posiciones de los platenses. Los días siguientes estuvieron marcados por continuos actos relámpagos en diversas arterias de la ciudad. En este marco, fueron detenidos 23 estudiantes latinoamericanos al cierre de una misa en la Iglesia San Ponciano. Este era el panorama cuanto el 12 de septiembre llegó la noticia de la muerte del cordobés Santiago Pampillón. El trágico suceso modificó las posiciones en el mapa estudiantil. Una parte de las fuerzas que habían apoyado el gobierno militar, o habían tomado posturas realmente ambiguas al respecto, pasaron al "bando" de quienes lo repudiaban. Este punto del año nos sirve como marco para realizar una breve presentación de actores, es que un ejemplo claro de aquel "pasaje" lo encontramos entre las agrupaciones peronistas y la Federación Universitaria para la Revolución Nacional (FURN), una de las protagonistas de la vida universitaria del período. Si bien los encuentros y el armado de este espacio datan de 1964, fue mediando 1966 que surgió “oficialmente" en una reunión de no más de 20 o 30 personas, con fuerte presencia de estudiantes peruanos, de Derecho, un grupo de Veterinarias y estudiantes de Humanidades, Medicina y Agronomía. En dicha reunión inicial se habría acordado el nombre FURN, una orientación política de apoyo expectante hacia la Revolución Argentina y la no participación en los espacios reformistas. Es decir, la salida de la FULP por considerar dicho movimiento como limitado en su capacidad para actuar en política por fuera de la universidad. El respaldo inicial a Onganía fue a las pocas semanas abandonado, a partir, como se dijo, del asesinato de Pampillón. La primera declaración pública que alude a esto fue del Movimiento Universitario de la Revolución Nacional de Veterinarias, el que se posicionó atribuyendo la responsabilidad por la muerte del estudiante al "liberalismo anti popular" y criticando, además, al reformismo por sostener una lucha de "consignas formales" y escasos reclamos "nacionales y populares" (El Día, 14/09/1966). ${ }^{2}$ Para mediados de 1968, la FURN tenía una presencia fuerte en Derecho, Humanidades y Veterinarias y grupos importantes en Económicas, Naturales y Bellas Artes; comenzó a funcionar con mayores grados de organicidad, conformando una Mesa de Dirección y proponiendo una doble militancia de sus miembros, en la FURN y la Juventud Peronista. Al mismo tiempo, en agosto de 1968 una reunión en Rosario comenzó a darle forma a una articulación nacional de agrupaciones peronistas y cristianas, a través de un manifiesto con un tono tan antidictatorial como antirreformista.

Desde el campo de estudios sobre el movimiento estudiantil argentino, se señala que, pasada una breve etapa de resistencia antidictatorial, los meses que transcurren entre fines de 1966 y 1967 muestran signos de una derrota de los universitarios seguida de una "retracción" que, salvo por el caso de Córdoba, se explica por los efectos del cierre de los canales institucionales y la fuerte represión. Todo cambio de etapa política, la represión y la derrota, provocan movimientos en los actores políticos. Y aunque las disidencias entre las corrientes estudiantiles no comenzaron en 1966, este año abrió una suerte de nueva etapa, con novedades, 
rupturas y reagrupamientos. El ya mencionado surgimiento de la FURN fue el primero de ellos. Sin dudas, esto significó una novedad en el mapa universitario: el armado de una suerte de coordinadora de agrupaciones peronistas que hacía de "competencia" al reformismo y la FULP. Pero dentro del reformismo también se sucedieron novedades que vale presentar.

La primera novedad en el campo reformista está dada por la creación de Unión Nacional Reformista "Franja Morada" (UNR-FM) a mediados de 1967, en Rosario. Con antecedentes que se remontan a 1964, la Unión agrupaba formalmente a espacios reformistas de Córdoba, Rosario y La Plata que resistían al gobierno militar pero no adherían a los métodos y propuestas de una FUA conducida por el reformismo de izquierdas. Los grupos que crearon la UNR-FM eran variados: radicales, pero también anarquistas, socialistas democráticos e independientes, identificados todos ellos con el reformismo, con la defensa del gobierno de Arturo Illia y con un fuerte tono anticomunista. Con algunas divergencias internas, este espacio fue conducción de la FULP desde 1962 hasta mediados de $1969 .^{3}$

Durante buena parte de los años 1950/1960 el comunismo y los espacios afines tuvieron un lugar clave en las universidades nacionales. En la UNLP, para 1966, las agrupaciones de izquierda comunista o filo comunista eran mayoritarias y mantenían importante presencia en Humanidades, Derecho, Arquitectura, Bellas Artes y Medicina, todas facultades con gran iniciativa política. Sin embargo, y a pesar de que otras escisiones habían marcado al PC platense en 1963/1964, ninguna fue tan honda como la que, entre 1967 y 1969, dio lugar al Partido Comunista Revolucionario y su brazo universitario, el Frente de Agrupaciones Universitarias de Izquierdas (FAUDI). En la UNLP, las agrupaciones conducidas por el PC pasaron a integrar la nueva corriente, que se convertirá en un actor clave para comprender las acciones y posiciones de la FUA y la FULP ${ }^{4}$ : hacia 1968, el FAUDI conducía los Centros de Estudiantes de Humanidades, Medicina, Naturales, Bellas Artes y Arquitectura. Este caso nos coloca frente a un dato clave de los años sesentas como es la profusión de nuevas agrupaciones que expresaban la complejidad de los debates, de las identidades y los procesos de escisiones y convergencias en las izquierdas argentinas. En la misma línea, cabe mencionar el caso de las agrupaciones identificadas con el trotskismo: por un lado, con las fracciones del Partido Revolucionario de los Trabajadores (PRT), algo más minoritarias pero con una presencia marcada y una tradición que, más allá de las rupturas, se remonta a 1959; y también aquellas referenciadas con Política Obrera, agrupadas en la Tendencia Estudiantil Revolucionaria Socialista (TERS).

Si los años 1966/1967 fueron más bien de repliegue del estudiantado, 1968 revierte esta tendencia. La chispa la encendió la protesta contra las restricciones al ingreso universitario, donde confluyeron reformistas de todo tipo (Franja Morada, comunistas, trotskistas y maoístas) y los peronistas de la FURN. En junio, las acciones estudiantiles se potenciaron con las de un sindicalismo que iba contra las políticas económicas del régimen. En abril de 1968, una decena de gremios platenses crea la Intersindical, una suerte de antecedente de la CGTA. Este espacio recién logrará armarse en julio, con un programa que, entre otros puntos, proponía una alianza con el movimiento estudiantil. ${ }^{5}$ Un poco antes, en junio, la FULP y la Intersindical convocaron a un acto conjunto que debió suspenderse debido al accionar policial. La represión tuvo sus consecuencias. Se sucedieron nuevos paros, actos relámpago, el cierre de la UNLP y la facultad de Arquitectura por algunos días. Tal dinámica se mantuvo hasta septiembre, dando forma al "Invierno Caliente" platense que tuvo como saldo alrededor de 500 detenidos en un solo día, una fuerte coordinación con la CGTA y una aceleración de la activación política estudiantil. Continuando el ritmo, entre septiembre y noviembre, tuvo lugar la conocida huelga petrolera en la Destilería de YPF que duró dos meses y fue realizada por siete mil trabajadores. Todo esto, un año antes del Cordobazo. 


\section{El precio de la libertad por la que luchamos. la Plata en mayo de 1969: CONFLICTOS Y ENFRENTAMIENTOS DIARIOS SIN UN "AZO"}

Pocos días antes de que tuviera lugar la insurrección cordobesa, el movimiento estudiantil nacional comenzó un ciclo de luchas que no se frenaría hasta, por lo menos, el mes de septiembre. Entre el 15 y el 21 de mayo de 1969 fueron asesinados tres estudiantes, uno en Corrientes y dos en Rosario, en el marco de protestas hoy recordadas como "azos". Y aunque en la ciudad de La Plata no se había sucedido un "azo", el 15 de mayo se abrió una suerte de espiral ascendente de acciones y conflictos que tomará más fuerza aún tras la noticia del Cordobazo. El panorama nacional, el escenario global y latinoamericano, y sus consecuencias en el mundo político argentino le otorgaron rápidamente un tono casi mítico.

El mismo 15 de mayo, una reunión de FULP a la que asistieron todos sus Centros, logró por unanimidad convocar un paro general en repudio del asesinato de Juan José Cabral en Corrientes. Pero el hecho ameritaba algo más que una reunión: un sector del organismo realizó un acto relámpago en el centro de la ciudad que finalizó con ataques al Banco de Crédito Provincial. Aunque la medida podría pensarse al azar, la FULP se encargó al otro día de aclarar que no lo era: "Los daños ocasionados anteayer en el Banco de Crédito no derivaron de una simple acción de terrorismo. Por el contrario el hecho tuvo plena significación de repudio: en dicha institución se deben abonar los aranceles fijados por la intervención." (El Día, 18/05/1969). Algo más ocurrió en esa reunión. Por diferencias internas, la FULP dejó de estar conducida por Franja Morada y pasó a manos de un FAUDI que sí actuaba en bloque y contaba con cinco Centros. El día del paro estudiantil coincidió con otra noticia trágica, había sido asesinado Adolfo Bello en Rosario: la UNLP entera fue cerrada por duelo, la FURN convocó una misa en la Catedral, Franja una "marcha del silencio" y el FAUDI un acto en el Comedor. Entre el 20 y el 28 de mayo, se sucedieron numerosas acciones de la FULP, FURN y organizaciones universitarias, todas ellas contestadas con una fuerte represión. Una serie de actos relámpago, un intento de colocar una placa recordatoria de Cabral y Bello en Ingeniería y una nueva misa convocada por FURN tuvieron como saldo inmediato alrededor de cien estudiantes detenidos, entre ellos Ricardo Campero, rosarino y dirigente nacional de FM y Guillermo Blanco, presidente de FULP. Pero también los lazos con otros actores de la ciudad comenzaron a tomar forma pues, en ese marco de enfrentamientos casi cotidianos, diversos grupos de docentes universitarios se solidarizaron con las luchas; lo hicieron también estudiantes de la Universidad Católica Argentina, convocando los de Arquitectura a una misa de homenaje a los estudiantes caídos y los de Derecho a una huelga; el Movimiento Peronista comenzó a convocar públicamente a las acciones y misas de la FURN y la CGTA y gremios como ATE y Unión Ferroviaria expresaron su solidaridad con los universitarios.

El 21 de mayo, en medio de una ciudad movilizada, ocurrió un hecho que nos pinta el tono de esos días. Todo comenzó a la mañana en la Facultad de Ingeniería, cuando un acto de FULP que iría a finalizar con la colocación de una placa recordatoria de Bello y Cabral y una Marcha del Silencio, fue reprimido. ${ }^{6}$ Esto provocó una concentración espontánea de 1000 estudiantes que se enfrentó con la policía y comenzó a dispersarse, sin que ello significara abandonar las calles. La táctica estudiantil adoptó entonces la forma de pequeños enfrentamientos y barricadas, llegando a contabilizarse seis para un radio que iba entre Avenida 1 hasta calle 6 y las calles 46 y 50. Pero ese día, el club Estudiantes de La Plata jugó y ganó la final de la Copa Libertadores de América en su estadio, en Avenida 1 y calle 54. Y cuando una larga columna de simpatizantes se movilizaba hacia los típicos festejos en la intersección de 7 y 50, se entremezcló con las acciones estudiantiles. Dice la crónica que, pese al despliegue policial un grupo de estudiantes llegó a encabezar la columna de simpatizantes del equipo local (que, para dimensionar, abarcaba unas diez cuadras) y cambiando cánticos, lanzaron consignas contra el gobierno y en favor de la lucha estudiantil. Entre los simpatizantes, algunos aplaudieron, gritaron "asesinos" a la policía y se sumaron a los slogans contra la dictadura militar. Aunque la policía arrojó gases y hubo corridas, la represión no dejó saldos mayores. Los días siguientes continuaron con esta dinámica. Durante el día 24, por ejemplo, y tras la prohibición de un 
acto de FULP, la zona céntrica de la ciudad estuvo repleta de barricadas estudiantiles, actos relámpago y enfrentamientos con la policía. Una concentración frente al diario El Día llevaba una bandera con la frase "Pagarán cara la sangre de los estudiantes caídos bajo las balas de la dictadura". Ninguna forma de protesta escapó por estos días a la feroz represión. La misa que la FURN había organizado para el día 28 fue realmente masiva. A su fin, 500 estudiantes marcharon por el centro de la ciudad y se enfrentaron con la policía, con barricadas, bombas caseras y cánticos como "Bello, Cabral, los vamos a vengar". Los combates duraron poco más de una hora y se trasladaron por diversos puntos de la ciudad; al final, la FURN denunció unas 15 detenciones mientras las fuerzas policiales anunciaban que tal número era de tres.

Tal era el estado de cosas, en La Plata y en una buena parte de las ciudades del país, cuando tuvo lugar el paro general convocado por las dos CGT para el día 30 de mayo, al cual, como sabemos, la población obrera de Córdoba se le adelantó en un día. ${ }^{7}$ La FULP había manifestado su adhesión a la medida así como también, para el día 29 y en consonancia con la Jornada Nacional de Lucha anunciada por la FUA, asambleas en todas las Facultades y un acto frente al Rectorado para "manifestarse en repudio al régimen imperante". Las asambleas pudieron realizarse con éxito, pero el acto se desenvolvió como todos los anteriores, con fuerte represión policial y resistencia estudiantil. En este marco, tuvo lugar la detención en un bar de numerosos dirigentes, entre ellos, el presidente de la FULP (Guillermo Blanco) y el presidente del Centro de Estudiantes de Naturales, facultad que como veremos, se encontraba inmersa en un conflicto propio. A partir de los días 29 y 30 de mayo, se conforma un escenario local marcado por la radicalización de los actores y la efervescencia callejera. En concreto, esa radicalización adquirió varias formas: primero, una profundización de los métodos represivos aplicados por las fuerzas policiales; segundo, radicalización en las acciones y los discursos estudiantiles; tercero, radicalización de otros actores universitarios que tuvo como resultado conflictos y renuncias en cinco facultades. Todo ello acompañado de enfrentamientos callejeros diarios.

El sábado 31, una movilización de 300 estudiantes que finalizaba en el Comedor fue duramente reprimida. Con el establecimiento repleto, se arrojaron bombas de gases lacrimógenos en su interior, lo cual provocó un desbande y el intento de los estudiantes de salir mediante la rotura de los ventanales, de tres metros de altura y orientados hacia el Paseo del Bosque. Así, dentro del espacio y en las inmediaciones se realizaron decenas de detenciones, dos periodistas resultaron heridos y otros dos estudiantes debieron ser internados por las lesiones. Tanto la FULP, como Franja Morada y la FURN emitieron duros comunicados donde denunciaban la violencia policial y los destrozos en el Comedor, así como también la secuencia de allanamientos y detenciones, realizados en los domicilios de estudiantes durante dos noches consecutivas. Para el día 2 de junio, sabemos que cinco varones detenidos en allanamientos serían trasladados a la Unidad Carcelaria $\mathrm{n}^{\circ} 9$ y puestos a disposición de la Justicia Militar; a disposición de la misma quedaron cuatro mujeres, también detenidas en sus casas y trasladadas a la Brigada Femenina. Sabemos que entre las nueve detenciones se encontraban los presidentes de los Centros de Medicina y Ciencias Naturales, del FAUDI; a ello debemos sumar que unos días antes, había ocurrido lo mismo con Néstor Brutti, presidente del Centro de Humanidades, también del FAUDI. Con el correr de los días, los nueve fueron liberados mediante el recurso Habeas Corpus, con la excepción de Brutti. No fue esto un tema menor. Los últimos días de mayo, comenzó un fuerte conflicto en la Facultad de Humanidades, suscitado alrededor del caso: el decano de la misma habría solicitado que Brutti sea juzgado por tribunales militares, generando el repudio de todas las corrientes estudiantiles (la FURN entre ellas) y docentes que mantuvo paralizada a la Facultad hasta que se logró su liberación el 11 de junio, en medio de fuertes rumores de renuncia del Decano, Raúl Balbé. Por esos días se encontraban inmersas en conflictos similares Ciencias Naturales (cuyo decano había sancionado al presidente del Centro de Estudiantes), Derecho (donde las autoridades habían dispuesto un control de identidad en el ingreso a la facultad), Arquitectura y Veterinarias. Como sucedía desde 1966, todas las esferas de la UNLP se enfrentaban al cuestionamiento estudiantil hacia las autoridades gubernamentales y universitarias, representantes directas del régimen dictatorial. 
El citado trabajo de los cordobeses Crespo y Alzogaray (1994) señala varios elementos propios del clima "del '69" que vale pensar para nuestro caso. Entre ellos, podemos remarcar dos que, sin ser sinónimos, se habrían convertido en notas comunes a todas las corrientes del movimiento estudiantil: la fuerte conciencia antidictatorial y la extendida desconfianza hacia las autoridades. Por momentos, ambas permitieron al movimiento estudiantil actuar de forma unificada, es decir, como "movimiento social" cohesionado por un reclamo antidictatorial, antes que como corrientes políticas. Aquellos episodios de feroz represión representaron para los platenses, algunos de esos momentos de confluencia. Ahora bien, en diálogo con lo reseñado en la Introducción, los autores afirman que aquel rechazo a la autoridad se tradujo también en una crítica hacia las instituciones clásicas del movimiento estudiantil, heredadas de la Reforma Universitaria de 1918: los Centros, las Federaciones y la figura de la representación. La creación de nuevos espacios, la preeminencia de la acción directa por sobre la institucional (prácticamente vedada), y el pasaje de la política gremial a la política "a secas", habrían sido las consecuencias prácticas de dicho rechazo. Y si el primer rechazo aparece con claridad en nuestra historia platense, no sucede lo mismo con el segundo. Aquí, el abandono de los espacios clásicos del estudiantado tiene lugar aunque de forma matizada, esto es, mediante prácticas y discursos que tuvieron una presencia importante, aunque no mayoritaria y en convivencia con otras posturas que sí continuaban valorándolas.

Como podemos suponer, los discursos más críticos hacia la trama de instituciones estudiantiles heredadas del reformismo fueron encarnados por la FURN y el Grupo Universitario Liberación (GUL), espacios que las más de las veces actuaban de forma coordinada. Ya en octubre de 1967, el GUL emitió un extenso boletín titulado, justamente, “¿Porqué no las elecciones?”. Sus tres páginas realizaban una fuerte crítica a las elecciones de Comisiones Directivas de los Centros, caracterizando el voto como un "criterio burocrático" y a la FULP como un espacio inoperante y gastado. ${ }^{8}$ Durante los meses más álgidos de 1969, la FURN y el GUL propusieron "buscar nuevas formas organizativas", un trabajo más cercano entre ambas y la incorporación de estudiantes independientes. En septiembre del mismo año, en ocasión del aniversario del asesinato de Santiago Pampillón, la FURN lo caracterizó como el hecho que hizo entrar al reformismo en "el país real", abogando al conocido mito de la "isla democrática". ' Sin embargo, la organización peronista no dejó de asistir a la colocación de una placa recordatoria del cordobés, acto organizado por el Centro de Estudiantes de Derecho, donde hicieron de oradores un representante de la CGTA, Domingo Teruggi por Franja y Rodolfo Achem por FURN.

Cabe también mencionar la creación de Comités de Resistencia en algunas facultades, como Ciencias Naturales, y la apuesta del FAUDI al armado de una Coordinadora Intercentros, paralela a la FULP. Aquí la existencia de críticas y propuestas de superación no fueron sinónimos automáticos de abandono; esto es, afirmar que existió un discurso de rechazo, no quiere decir que no se hayan compartido espacios ni banderas con un reformismo y una FULP que seguían siendo una referencia para los platenses. ${ }^{10}$ Incluso, y de acuerdo a la reconstrucción que arriba realizamos, es innegable que la FULP condujo buena parte de las acciones más importantes del año, así como también lo es que las agrupaciones directamente identificadas con esos espacios clásicos, como Franja Morada ${ }^{11}$, no desaparecieron del mapa, al contrario, conducía Centros sumamente activos como Derecho e Ingeniería. Al mismo tiempo, las organizaciones que encarnaban los discursos más políticos y radicalizados, como el FAUDI y la TERS, tampoco abandonaron los espacios reformistas, aunque sí los disputaron e intentaron resignificarlos, en el caso de la primera, y criticarlos fuertemente "desde su interior", en el caso de la segunda. Durante el año 1969 fueron numerosas las actividades que encontraron a todas las tendencias. El aniversario de la Reforma Universitaria no fue la excepción: en la asamblea-homenaje organizada por la FULP el 16 de junio participaron Franja, el FAUDI, el MOR, la TERS y Sergio Karakachoff por los graduados, con discursos que vale la pena repasar. En principio, solo uno atacó directamente al reformismo por considerarlo insuficiente para el momento político. Estas palabras fueron expresadas por el militante de la TERS, que además llamó a conformar "comisiones de resistencia" en todas las Facultades. También un representante de la agrupación MAU de Arquitectura convocó a un nuevo 
formato de organización, las "comisiones coordinadoras de lucha" integradas con un movimiento obrero por entonces movilizado. Luego, Karakachoff, un tal Rodolfo Urbina del MOR y Domingo Teruggi (presidente del Centro de Derecho y de Franja) coincidieron en convocar a la unidad del movimiento estudiantil en la oposición a la dictadura; y, finalmente, el FAUDI llamó a ocupar las Facultades y repudiar la visita al país de Nelson Rockefeller.

Durante los meses que siguieron, la conflictividad platense se mantuvo en alza no solo porque continuaron las acciones estudiantiles contra un gobierno cada vez más represivo. También, y por esa razón, comenzó a ganar cuerpo una coordinación más fluida con sectores del movimiento obrero, en particular, con una CGTA que se sumó activamente a los homenajes realizados por el aniversario del asesinato de Pampillón en septiembre, mientras los estudiantes adherían a las huelgas generales convocadas por la entidad, como la del primero de julio y la más exitosa del 27 de agosto. También, resultó más articulada la solidaridad con gremios como Unión Ferroviaria de Tolosa, en lucha durante septiembre, y la Asociación de Trabajadores de la UNLP. ${ }^{12}$ Rápidamente, sin embargo, las consignas estudiantiles se enfocarán en el aniversario del asesinato del "Che" Guevara.

\section{Palabras Finales}

Una reconstrucción como la presentada en las páginas anteriores nos muestra, al menos, dos cosas. Por un lado, no observamos para La Plata un movimiento de rebelión popular similar al Cordobazo, aunque las calles de la ciudad se convirtieron en algo así como un hervidero para el último día de mayo de 1969. Tal como sugiere Juan Califa (2018) para el caso porteño, un elemento clave para iluminar aquella diferencia radica en la situación del movimiento obrero platense: su fracción opositora, agrupada en la CGTA, tenía una presencia importante pero débil, al no llegar a agrupar a los sindicatos más numerosos. Además, los conflictos de 1968/1969 protagonizados por los petroleros de la Destilería de YPF y los gráficos de Fabril Financiera (en enero de 1969), debilitaron la imagen y la propuesta de una CGTA afectada además por la política represiva del gobierno. Mayo de 1969 encuentra a un sindicalismo opositor en posición defensiva. Las diversas corrientes del movimiento estudiantil sí mantuvieron altos niveles de dinamismo y radicalidad. Pero sin un movimiento obrero en similar posición, difícilmente fuera a "encenderse" la ciudad o a lograrse algo así como una rebelión popular que canalizara una percepción social de injusticia y un hartazgo hacia el autoritarismo que sí estaban disponibles entre los actores, organizados y no, de la ciudad. Quizás el "Invierno Caliente" de 1968 fuera lo más parecido a un "azo" que tuvo la ciudad, no obstante, en una coyuntura nacional completamente distinta, aún no preparada para que la protesta masiva expresara aquellas percepciones.

Por fuera de un balance realista entre correlaciones de fuerzas y oportunidades políticas abiertas, hay otro aspecto a resaltar. La crónica periodística, la palabra de los y las protagonistas, así como de los restantes actores del momento, nos hablan de un movimiento estudiantil que, desde La Plata, estuvo a tono con los "global sixties", esa revuelta de la juventud con rasgos tan internacionales como métodos radicales. Entre mayo y junio de 1969, El Día registró levantamientos estudiantiles en Estados Unidos, Alemania Federal, Venezuela, Colombia, Ecuador, Uruguay, Chile y Perú, para el 31 de mayo afirmar en su editorial que el país estaba en medio de un "clima de violencia". Más interesante resultó una declaración efectuada por 16 profesores y 8 profesoras de la Facultad de Humanidades que, solidarizándose con los estudiantes proponía dos claves de análisis para la situación en la UNLP: primero, afirmaban que la crisis de la Universidad argentina tenía causas comunes con conflictos similares en el mundo, entre ellas, el desborde masivo de las aulas y la acción de una juventud que "afirma su mayoría de edad histórica"; segundo, en las universidades argentinas esos factores comunes eran completados con el autoritarismo, la ausencia de diálogo y la exclusión de importantes actores en la toma de decisiones; tercero, más concreto aún, todo eso se observaba en la UNLP a través de la supresión de materias y carreras sin previo debate, el debilitamiento de la formación nacional, entre otros puntos. ${ }^{13}$ Hemos recuperado estas palabras porque, como afirmamos al comienzo, es importante observar procesos 
generales a través de análisis concretos. En este caso, intentamos rastrear las particularidades del estudiantado platense, sus acciones, sus discursos antidictatoriales así como también aquellas críticas a las banderas y espacios reformistas, en el marco de un ciclo nacional de levantamientos estudiantiles como el sucedido en mayo de 1969. Y si la primera cuestión aparece con claridad en nuestra historia, no sucede lo mismo con la segunda. El "Invierno Caliente" de 1968 y el sinnúmero de movilizaciones estudiantiles de mayo de 1969 no dejan lugar a dudas sobre el hartazgo estudiantil hacia las autoridades estatales y universitarias. Sin embargo, el abandono de los espacios clásicos del estudiantado se dio de forma matizada, esto es, mediante prácticas y discursos que tuvieron una presencia importante como fue la de la peronista FURN y otras más pequeñas como GUL y las trotskistas, pero no era mayoritarias. Actuaban, además, en convivencia con otras posturas que sí continuaban valorándolas: Franja Morada y el MOR, identificadas totalmente con el Reformismo, y el FAUDI, con una propuesta más intermedia que proponía al mismo tiempo, reforzar los Centros de Estudiantes y la FULP y crear nuevos espacios para cuando los clásicos fallaran. Quizás un trabajo que explore sobre las consecuencias de 1969 entre el estudiantado coloque sobre la mesa aquel "agotamiento histórico" del reformismo que, sin dudas, hacia 1973 podría ser un hecho. Hemos querido aquí observar los matices y pliegues de la historia del movimiento estudiantil platense que nos permita, finalmente, darle un ritmo propio a aquellas lecturas generales del período que iluminan y orientan las investigaciones locales, pero deben complementarse en los detalles.

\section{Fuentes}

Base de Datos construida por Bonvena, P. (1992) en Las luchas estudiantiles en Argentina 1966/1976. Informe de Beca de Perfeccionamiento, Secretaría de Ciencia y Técnica, Universidad de Buenos Aires.

Documento Confederación General del Trabajo, CGT - Tomo II (1955-1973), en: CPM - Fondo DIPBA,

División Central de Documentación, Registro y Archivo. Mesa B, Carpeta Gremial, Leg. 137.

Documento Grupo Universitario Liberación, en: CPM - Fondo DIPBA, División Central de Documentación, Registro y Archivo. Mesa A, Factor Estudiantil, Leg. 157.

Documento FAUDI, en: CPM-Fondo DIPBA, División Central de Documentación, Registro y Archivo. Mesa A, Factor Estudiantil, Leg. 198.

Diario El Día, La Plata. Consultado de enero a diciembre de 1969.

Diario La Nación, Buenos Aires. Consultado de mayo a junio de 1969.

Nueva Hora, Órgano del PC-CNRR, consultado entre junio de 1968 y junio de 1969. Archivo Nacional de la Memoria, Ciudad de Buenos Aires.

\section{REFERENCIAS}

Alzogaray, D. y Crespo, H. (1994). Los estudiantes en el mayo cordobés. Estudios 4, 75-90. Recuperado de: https://r evistas.unc.edu.ar/index.php/restudios/article/view/14306

Barletta, A. (2000). Universidad y política. La "Peronización" de los universitarios (1966-1973). Elementos para rastrear la constitución de una política universitaria peronista. Ponencia presentada en Congreso LASA 2000, Estados Unidos. Recuperada de: http://lasa.international.pitt.edu/Lasa2000/Barletta.PDF

Beltrán, M. (2013) La Franja. De la experiencia universitaria al desafio del poder. Buenos Aires: Aguilar.

Bozza, A. (2010). Espías, disturbios y barricadas. La radicalización estudiantil y los servicios de información. La Plata, 1968. En Infesta M. E. (coord.) El centenario de los estudios históricos en La Plata. La Plata.

Bonavena, P. (2006). El movimiento estudiantil de la ciudad de La Plata (1966-1973). Cuestiones de Sociología 3, 169-192. Recuperado de: https://www.cuestionessociologia.fahce.unlp.edu.ar/article/view/CSn03a07 
Bonavena, P. y Califa, J. (2018). El '68 argentino. Luchas estudiantiles en los albores de un ascenso de masas. En Bonavena, P. y Millán, M. (eds.). Los '68 latinoamericanos: movimientos estudiantiles, política y cultura en México, Brasil, Uruguay, Chile, Argentina y Colombia (pp. 201-232). Buenos Aires: IIGG-CLACSO.

Brennan, J. y Gordillo, M. (1994). Protesta obrera, rebelión popular e insurrección urbana en la Argentina: el Cordobazo. Estudios 4, 51-74. Recuperado de: https://revistas.unc.edu.ar/index.php/restudios/article/view/1 4305

Califa, J. (2015). Del Partido Comunista al Partido Comunista Comité Nacional de Recuperación Revolucionaria en la Argentina de los años sesenta. Una escisión con marca universitaria. Izquierdas 24, 173-204. Recuperado de: http://www.izquierdas.cl/images/pdf/2015/n24/8.pdf

Califa, J. (2018). El '69 porteño. El ascenso de masas en la Universidad de Buenos Aires y su contexto. Argumentos: revista de critica social 20, 77-99. Recuperado de: https://publicaciones.sociales.uba.ar/index.php/argumentos/ article/view/3093/2543

Cappannini, A., Massano, J. P., Romá, P. (2012). La formación de la CGT de los Argentinos en La Plata, Berisso y Ensenada al calor del '68 platense: La experiencia de la intersindical de gremios y sus relaciones con el movimiento obrero y estudiantil. Trabajo presentado en las VII Jornadas de Sociología de la UNLP, Argentina. Recuperado de: http://www.memoria.fahce.unlp.edu.ar/trab_eventos/ev.1771/ev.1771.pdf

Cisilino, J. (2016). Izquierda y nueva izquierda en los orígenes del Partido Comunista Revolucionario (1967-1969). Trabajo presentado en las IX Jornadas de Sociología de la UNLP, Ensenada. Recuperado de: http://www.mem oria.fahce.unlp.edu.ar/trab_eventos/ev.8873/ev.8873.pdf

Ceballos, C. (1985) Los estudiantes universitarios y la politica 1955-1970. Buenos Aires: Centro Editor de América Latina.

Gordillo, M. (2003) Protesta, rebelión y movilización: de la resistencia a la lucha armada; 1955-1976. En James, D. (coord.) Violencia proscripción y autoritarismo. Nueva Historia Argentina. Tomo IX. Buenos Aires: Sudamericana.

Hernández Arregui, J.J. (2011) La formación de la conciencia nacional. Buenos Aires: Peña Lillo.

James, D. (2010) Resistencia e Integración. Buenos Aires: Siglo XXI.

Manzano, V. (2017) La era de la juventud en Argentina. Cultura, política y sexualidad desde Perón hasta Videla. Buenos Aires: FCE.

Millán, M. (2013). Entre la Universidad y la política. Los movimientos estudiantiles de Corrientes, Resistencia, Córdoba y Tucumán durante la "Revolución Argentina" (1966-1973), (Tesis doctoral inédita). UBA, Buenos Aires.

Millán, M. (2018). Un análisis crítico de las interpretaciones sobre los movimientos estudiantiles de los '60. En Bonavena, P. y Millán, M. (eds.). Los '68 latinoamericanos: movimientos estudiantiles, politica y cultura en México, Brasil, Uruguay, Chile, Argentina y Colombia (23-52). Buenos Aires: IIGG-CLACSO.

Nava, A. (2012). Conflictividad del movimiento estudiantil y de la clase obrera platense durante el año 69. Algunos elementos para su estudio. En Castillo, C. y Raimundo, M. (comps.) El 69 platense (155-198). Buenos Aires: Estudios Sociológicos.

O' Donnell, G. (2009). El Estado burocrático autoritario. Buenos Aires: Prometeo.

Pis Diez, N. (2018a). Universidad, politica y radicalización en el posperonismo : el caso de la Universidad Nacional de La Plata y su movimiento estudiantil reformista (1955-1966) (Tesis doctoral). Recuperada de: http://www.memor ia.fahce.unlp.edu.ar/tesis/te.1678/te.1678.pdf

Pis Diez, N. (2018b). Reforma Universitaria y Liberación Nacional. Las "primeras" agrupaciones peronistas y los orígenes de la FURN en La Plata (1962-1966). Estudios 40, 57-73. Recuperado de: https://revistas.unc.edu.ar /index.php/restudios/article/view/20951

Recalde, A. y Recalde, I. (2007) Universidad y liberación nacional. Buenos Aires: Nuevos Tiempos.

Torre, J. C. (1994). A partir del Cordobazo. Estudios 4,15-24. Recuperado de: https://revistas.unc.edu.ar/index.php /restudios/article/view/14299 


\section{Notas}

1 Una reconstrucción pormenorizada de las consecuencias inmediatas del golpe en la UNLP, ver en Pis Diez (2018a). Este apartado es una sucinta versión de ella.

2 Una reconstrucción detallada de los “grupos iniciales” ver en Pis Diez (2018b). Aquí encontramos que hasta 1966, la mayoría de ellos sí actuaba en la FULP, participaba de elecciones y articulaba con el reformismo de izquierdas. El cambio de régimen político y la prohibición de la actividad estudiantil y reformista, generaba un espacio vacante para el espacio universitario peronista, por lo cual, acuciaba organizar un nuevo discurso.

3 En agosto de 1963, una reunión nacional en Rosario fue el paso inicial para organizar un bloque, cuyas coincidencias radicaban en puntos como el repudio a los "totalitarismos de izquierda y derecha", la oposición a la línea política de la FUA y el acuerdo en movilizarse por mayor presupuesto. En octubre de 1964, tuvo lugar otra en La Plata, con la presencia de Humanistas y varias agrupaciones reformistas de todo el país. Aquí el debate fue acompañado de paneles con Carlos Bianchi, anarquista y rector de la UNLP, y Eduardo Schaposnik, disputado nacional del PSD. A los diez días, la reunión se replicó en Córdoba con mayor concurrencia de organizaciones santafesinas y cordobesas, como el Movimiento Integralista y la Unión Reformista Franja Morada. Allí fue ratificado lo debatido en la reunión anterior que acabó plasmado en la denominada "Declaración de La Plata". 1966 alejaría a los espacios cristianos del espacio y consolidaría el reformista. En la UNLP este espacio contaba con los Centros de Derecho, Ingeniería y Ciencias Económicas, y presencia fuerte en Humanidades, Arquitectura y Medicina. La reconstrucción se basa en Pis Diez, 2018 a. Ver también Beltrán (2013).

4 Para el caso de La Plata, Juan Cisilino (2016) afirma (retomando las palabras de Otto Vargas, entonces secretario del PC platense) que confluyeron el sector universitario, cuadros sindicales comunistas del frigorífico Swift-Armour, la dirección de la Lista Verde de Astilleros Río Santiago, una célula de la Destilería de YPF o la dirección de la Unión Ferroviaria de Tolosa. En total, habrían sido alrededor de cuatrocientos afiliados que, en La Plata, participaron de la ruptura. Para las causas políticas del hecho ver Cisilino y Califa (2015). Luego de la ruptura, el espacio comunista universitario logrará rearmarse, apareciendo hacia 1968 bajo el nombre de Movimiento de Orientación Reformista (MOR), con escaso peso en las aulas platenses.

5 Los gremios que integraron la CGTA eran alrededor de quince, entre ellos, Textiles, ATE, UPCN, Gas del Estado, los de los empleados de Educación y Salud, entre otros. De acuerdo a la información obtenida en los informes de la DIPBA, sabemos que ninguno de los gremios más grandes de la ciudad (como el de empleados de Comercio, Carne o Petroleros) adhirió; los integrantes del nuevo espacio eran más bien intermedios (ATE-La Plata contaba con cinco mil afiliados, Empleados de Educación con 3.900, por ejemplo). El total de afiliados para la ciudad se contabiliza en 90 mil. Ver Cappanini, Massano y Romá (2012); los números son de Documento Confederación General del Trabajo, CGT - Tomo III (1964-1973), CPM - Fondo DIPBA.

6 La nota de El Día dice al respecto "A puertas cerradas, y mientras el exterior estaba profusamente vigilado, y a la vez desierto, el Centro de Estudiantes de Ingeniería descubrió una placa recordatoria de los dos estudiantes nombrados. La placa, ubicada junto a la colocada en homenaje a Santiago Pampillón, dice: Bello, Cabral, vuestra sangre, que es la del pueblo oprimido, es el precio de la libertad por la que luchamos. Mayo, 1969. FULP” (ElDía, 22/05/1969). El mismo diario informó que a la Marcha del Silencio había adherido, por resolución del secretariado nacional, la CGTA; además, Eduardo de Luca (su Secretario de prensa nacional) asistió al acto. Manifestaron su adhesión al acto otros gremios, como ATE y Judiciales Bonaerenses (El Día, 21/05/1969).

7 De acuerdo a la crónica de El Día, el paro en la región tuvo un impacto parcial, es decir, la adhesión no fue total aunque tampoco pasó desapercibido. Por un lado, habrían tenido una actividad normal el comercio, los bancos, la Destilería de YPF, los frigoríficos de Berisso y el transporte automotor. Por otra parte, el servicio de trenes estuvo paralizado (hubo servicios de emergencia conducidos por personal superior) y también organismos estatales como Correos y Telecomunicaciones, Tribunales, Servicios Eléctricos, la Universidad de La Plata. Los gremios integrantes de la CGTA, como ATE, UPCN, Judiciales, Gas del Estado, UF-Tolosa, Municipales, entre otros, adhirieron por completo a la medida. En ocasión del día 30, la CGTA emitió un comunicado muy crítico del gobierno, convocando a la unidad con la juventud universitaria (El Día 30 y 31/05/1969).

8 Documento “Grupo Universitario Liberación”, CPM - Fondo DIPBA, Leg. 157. De acuerdo al informe, podemos decir que el espacio estaba conformado por integrantes del Movimiento de Liberación Nacional (MLN o Malena) y ex integrantes el Socialismo de Vanguardia. Entre 1967-1969, la mayor parte de sus acciones y comunicados se hacían conjuntamente con la FURN.

9 En agosto de 1968, la FURN había colocado su sello a un manifiesto nacional de agrupaciones peronistas que señalaba respecto de 1966 que “(...) Esta nueva situación que plantea la dictadura viene demostrando a los estudiantes que sus banderas particulares (tales como autonomía, cogobierno, etc) ya no pueden tener vigencia en el marco de una dictadura castrense y reaccionaria. A su vez la caducidad de las instituciones liberales les impide canalizar a través de ellas sus 
reivindicaciones especificas. Así lo demostró el callejón sin salida en que terminó la lucha estudiantil, aislada, de los primeros momentos de la intervención dictatorial en las universidades." (documento citado en Hernández Arregui, 2011, p. 408).

10 Incluso, la crónica que realiza el FAUDI del "Invierno platense" otorga a los reclamos gremiales un lugar clave: " $L a$ luch a contra los aranceles, la supresión de los turnos mensuales de exámenes, la suspensión del tope de materias y aplazos como condición para la regularidad, constituyen ejes reivindicativos centrales y permanentes alrededor de los cuales el levantamiento de las sanciones a los estudiantes y la reapertura inmediata de los Centros, el retiro de la policía y la libertad de expresión, cobran importancia decisiva en esta etapa. Todo ello, proyectando a niveles superiores la resistencia generalizada a la politica de intervención y a crear condiciones para aportar, desde el ángulo universitario a la contraofensiva obreroestudiantily popular contra la dictadura". En medio de este balance encontramos una fuerte crítica a Franja por oponerse (con su posición "frenadora") a realizar una huelga estudiantil en ocasión del aniversario de la Reforma Universitaria; también hay una crítica a la FURN por su propuesta de sólo adherir a un acto de la CGT, cuestión que, de acuerdo al FAUDI colocaría al estudiantado "a la cola" de una fuerza heterogénea, sin iniciativa propia. En: "La lucha platense", Nueva Hora. Órgano del PC-CNRR, n. 9 (segunda quincena, julio 1968). Califa (2018) encuentra en la FAUDI de la UBA posiciones similares a las platenses, que proponían preservar los reformistas clásicos estrechando lazos con los novedosos. Para el autor esto habla de una suerte de "encrucijada" de una organización que debía reconocer lo nuevo sin perder su lugar en una FUA que conducía

11 Incluso para un espacio que no dejó de reconocerse reformista, las acciones no universitarias también debían tener un lugar predominante en la coyuntura de mayo de 1969. Por ejemplo, decía Ricardo Campero (rosarino, dirigente nacional de FM) en ocasión de un viaje a La Plata para compartir lo sucedido en su ciudad: "Nuestro movimiento es de carácter estudiantil pero está integrado con algo mucho más amplio: el movimiento del pueblo. En consecuencia, si bien los actos y las manifestaciones no fueron manejados por tendencias ajenas, puede asegurarse que tanto nuestra acción como la repulsa general, tuvo un fuerte contenido politico. Se trata de la luch a del pueblo contra el gobierno imperante, luch a democrática para terminar con la dictadura." (El Día 25/05/1969).

12 Tanto la FULP como FURN apoyaron activamente a la Unión Ferroviaria local, en el marco de la huelga nacional ferroviaria de mediados de septiembre. Recién al mes siguiente, seis estudiantes detenidos en la ocasión fueron liberados. Luego, el 1 y 2 de octubre la FULP se plegó a las huelgas de los trabajadores de la UNLP, logrando paralizar la universidad.

13 La nota estaba firmada por 24 docentes de la Facultad, entre ellos, hoy más conocidos, Rodolfo Agoglia, José María Lunazzi, José Panettieri, Néstor García Canclini, Ricardo Nasiff, Horacio Pereyra y Norberto R. Bustamante (El Día, 7/06/1969). Diez años después, Juan Carlos Portantiero haría una interpretación similar del fenómeno. 